Article

\title{
Investigation of the Pharmacological Properties of Lepidagathis hyalina Nees through Experimental Approaches
}

\author{
Fowzul Islam Fahad ${ }^{1,+}{ }^{\dagger}$ Niloy Barua ${ }^{1,+}{ }^{\dagger}$ Md. Shafiqul Islam ${ }^{1}$, Syed Al Jawad Sayem ${ }^{1}$, Koushik Barua ${ }^{1}$,

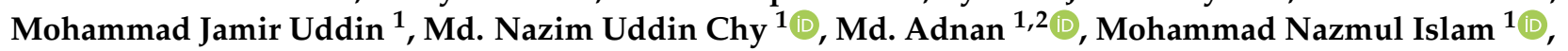 \\ Mohammed Aktar Sayeed ${ }^{1, *}$, Talha Bin Emran ${ }^{3, * \mathbb{D}}$, Jesus Simal-Gandara ${ }^{4, *} \mathbb{C}$, Ester Pagano ${ }^{5}$ \\ and Raffaele Capasso ${ }^{6, *(1)}$
}

check for

updates

Citation: Fahad, F.I.; Barua, N.; Islam, M.S.; Sayem, S.A.J.; Barua, K.; Uddin, M.J.; Chy, M.N.U.; Adnan, M.; Islam, M.N.; Sayeed, M.A.; et al. Investigation of the Pharmacological Properties of Lepidagathis hyalina Nees through Experimental Approaches. Life 2021, 11, 180. https://doi.org/ $10.3390 /$ life11030180

Academic Editor: Stefania Lamponi

Received: 28 January 2021

Accepted: 22 February 2021

Published: 25 February 2021

Publisher's Note: MDPI stays neutral with regard to jurisdictional claims in published maps and institutional affiliations.

Copyright: (C) 2021 by the authors Licensee MDPI, Basel, Switzerland. This article is an open access article distributed under the terms and conditions of the Creative Commons Attribution (CC BY) license (https:/ / creativecommons.org/licenses/by/ $4.0 /)$.
1 Department of Pharmacy, International Islamic University Chittagong, Chittagong 4318, Bangladesh; fowzul.fahad19@gmail.com (F.I.F.); niloybaruaniloy@gmail.com (N.B.); shafiqulislam.pharmacy@gmail.com (M.S.I.); aljawadsayem@gmail.com (S.A.J.S.); antukoushik@gmail.com (K.B.); jamiruddin3775@gmail.com (M.J.U.); nazim@gustoarg.org (M.N.U.C.); mdadnan@kangwon.ac.kr (M.A.); nazmul@iiuc.ac.bd (M.N.I.)

2 Department of Bio-Health Convergence, College of Biomedical Science, Kangwon National University, Chuncheon 24341, Korea

3 Department of Pharmacy, BGC Trust University Bangladesh, Chittagong 4381, Bangladesh

4 Nutrition and Bromatology Group, Department of Analytical and Food Chemistry, Faculty of Food Science and Technology, Ourense Campus-University of Vigo, E32004 Ourense, Spain

5 Department of Pharmacy, University of Naples Federico II, 80131 Naples, Italy; ester.pagano@unina.it

6 Department of Agricultural Sciences, University of Naples Federico II, 80055 Portici, Italy

* Correspondence: sayeed_ustc@iiuc.ac.bd (M.A.S.); talhabmb@bgctub.ac.bd (T.B.E.); jsimal@uvigo.es (J.S.-G.); rafcapas@unina.it (R.C.); Tel.: +880-1554-310162 (M.A.S.); +880-1819-942214 (T.B.E.); +34-988-387000 (J.S.-G.); +39-081-678664 (R.C.)

+ These authors contributed equally to this work.

Abstract: Lepidagathis hyalina Nees is used locally in Ayurvedic medicine to treat coughs and cardiovascular diseases. This study explored its pharmacological potential through in vivo and in vitro approaches for the metabolites extracted (methanolic) from the stems of L. hyalina. A qualitative phytochemical analysis revealed the presence of numerous secondary metabolites. The methanol extract of L. hyalina stems (MELHS) showed a strong antioxidative activity in the 1,1-diphenyl-2picrylhydrazyl (DPPH) and reducing power assays, and in the quantitative (phenolic and flavonoid) assay. Clot lysis and brine shrimp lethality bioassays were applied to investigate the thrombolytic and cytotoxic activities, respectively. MELHS exhibited an expressive percentage of clot lysis (33.98\%) with a moderately toxic $(115.11 \mu \mathrm{g} / \mathrm{mL})$ effect. The in vivo anxiolytic activity was studied by an elevated plus maze test, whereas the antidepressant activity was examined by a tail suspension test and forced swimming test. During the anxiolytic evaluation, MELHS exhibited a significant dosedependent reduction of anxiety, in which the $400 \mathrm{mg} / \mathrm{kg}$ dose of the extract showed $78.77 \pm 4.42 \%$ time spent in the open arm in the elevated plus maze test. In addition, MELHS demonstrated dosedependent and significant activities in the tail suspension test and forced swimming test, whereas the $400 \mathrm{mg} / \mathrm{kg}$ dose of the extract showed $87.67 \pm 6.40 \%$ and $83.33 \pm 6.39 \%$ inhibition of immobile time, respectively. Therefore, the current study suggests that L. hyalina could be a potential source of anti-oxidative, cytotoxic, thrombolytic, anxiolytic, and antidepressant agents. Further study is needed to determine the mechanism behind the bioactivities.

Keywords: Lepidagathis hyalina; antioxidants; cytotoxic; thrombolytic; anxiolytic; antidepressant

\section{Introduction}

Free radicals such as reactive oxygen species (ROS) and reactive nitrogen species (RNS) are byproducts of several physiological and biological processes leading to oxidative stress in the human body. Biomolecules (e.g., DNA, protein, lipids, etc.) are damaged by the 
overproduction of such free radicals, which play an important role in generating numerous chronic diseases [1,2]. Several types of atherothrombotic diseases, such as myocardial or cerebral infarction, occur due to thrombosis. When a homeostatic imbalance occurs in an artery, thrombus or blood clots are formed, which block the vascular organs and produce fatal signs that ultimately cause death [3].

According to the World Health Organization (WHO), nearly 450 million people suffer from anxiety and multiple depressive disorders, which make up around $12.3 \%$ of the global burden of diseases [4,5]. Depression is the predominant disorder associated with forms of emotional and cognitive disablement, such as impaired thinking and activity, energy loss, apathy, etc. This psychiatric illness increases the risk of mortality (every year, 10 to 20 million people attempt suicide) [6]. In addition, anxiety, which is another psychiatric illness, is the sixth major contributor to non-fatal health suffering worldwide, according to the WHO [7-9].

Many genetic, environmental, psychological, and biological factors are involved in the progression of psychiatric disorders. Therefore, chronic pain and inflammation are linked to the onset of depression and the development of anxiety. The most daunting consideration with these agents is concern about their safety because of their unwanted side effects [10-17]. Current research has focused on developing potent and safer molecules for healing numerous disorders. Therefore, a drug which can generate activity against psychiatric disorders, scavenge ROS, and exhibit thrombolytic activities with a favorable safety profile, may be the best choice for both psychiatric and cardiovascular disorders. Interestingly, nature is the most prominent source of secondary metabolites that are helping in the discovery of new drug molecules with potency, efficacy, and favorable safety profiles. Numerous essential bioactive molecules (such as phenolics, saponins, terpenoids, alkaloids, etc.) of medicinal plants have explored multifaceted pharmacological targets that may be observed to be significant when compared with synthetically developed drugs $[18,19]$.

Lepidagathis hyalina Ness is a subtropical habituated wild herb plant of the Acanthaceae family, known as curved Lepidagathis. It has been prescribed in Ayurvedic medicine for the treatment of coughs and cardiovascular diseases. It is mainly found in South Asian countries. In Bangladesh, it is widely available in hill tract areas. A previously reported article on this plant reported that a bioactive compound, named triterpenoid saponin $(3-\beta-O-[\alpha$-L-rhamnopyranosyl $(1 \rightarrow 4) O-\beta$-D-glucopyranosyl]16- $\alpha$-hydroxy-olean12-en(13)-28-oic acid), had been isolated from the leaf of this plant. In addition, a previous pharmacological study of this plant has shown that it provides good antimicrobial activity against pathogenic bacteria and fungi $[20,21]$.

Until now, there have been very few scientific reports regarding this plant (L. hyalina), despite the fact that it is traditionally considered important. Therefore, we aim to investigate the quantitative phytoconstituents and scrutinize the antioxidant, cytotoxic, thrombolytic, and neuropharmacological activities of a methanol extract of L. hyalina stems.

\section{Materials and Methods}

\subsection{Chemicals and Equipment}

Methanol, Folin-Ciocalteu reagent (FCR), potassium ferricyanide, sodium carbonate, aluminum chloride, potassium acetate, hydrochloric acid, and sulfuric acid were obtained from Merck (KGaA, Darmstadt, Germany). Quercetin, trichloro-acetic acid (TCA), sodium acetate, gallic acid, ferric chloride, and 1,1-diphenyl-2-picrylhydrazyl (DPPH) were purchased from Sigma Chemical Co. (St. Louis, MO, USA). Diclofenac sodium and diazepam were obtained from Square Pharmaceutical Ltd. Bangladesh. Vincristine sulfate (1 mg/vial) and lyophilized streptokinase vial (1,500,000 IU) were purchased from Beacon Pharmaceutical Ltd. Bangladesh (Bhaluka, Mymensingh, Bangladesh). The absorbance of the experiment was recorded using an Ultra-Violet-Vis spectrophotometer (UVmini-1240, Shimadzu, Japan). Several chemicals of analytical reagent grade with specified references were used in this research. 


\subsection{Plant Materials}

In March 2019, stems of L. hyalina Ness were collected in a fresh condition from the Golden Temple Hill tract area, Bandarban, Chittagong-4600, Bangladesh. The sample was authenticated by Shaikh Bokhtear Uddin, Professor and Taxonomist, Department of Botany, University of Chittagong, Chittagong-4331, Bangladesh. The plant sample was then confirmed and identified by Mohammed Aktar Sayeed, Professor, Department of Pharmacy, International Islamic University Chittagong, Chittagong-4318, Bangladesh.

\subsection{Preparation of the Methanolic Crude Extract}

The collected stems of L. hyalina were dried for 14 days in shade. Dried stems were then ground into a coarse powder through an automated grinder and dried in a mechanical drier at $60-70{ }^{\circ} \mathrm{C}$. The fine stem powder was submerged in an adequate volume of methanol for ten days at room temperature, and the solution was then shaken vigorously. After this process, the solution was filtered using a rotary evaporator and dried at a temperature of $40-50{ }^{\circ} \mathrm{C}$ in a water bath. A sticky semi-solid with a deep green color was formed. This was preserved in a refrigerator and used as methanol extract.

\subsection{Standardization and Quality Control of the Extract}

The methanol extract of L. hyalina stems (MELHS) was standardized and quality and physiochemical control of the crude extract was undertaken to ensure the safety and acute toxicity study of animal models [22].

\subsection{Phytochemical Screening}

Preliminary qualitative phytochemical analysis of MELHS was performed by the standard method for the determination of phytochemicals such as carbohydrates, alkaloids, protein, quinones, saponins, tannin, starch, phenols, flavonoids, unsaturated sterols and triterpene, cardiac glycoside, and coumarins $[23,24]$.

\subsection{In Vitro Antioxidant Activity}

\subsubsection{DPPH Free Radical Scavenging Assay}

Free radical scavenging of MELHS was conducted according to the method described by Barca et al. [25]. About $3 \mathrm{~mL}$ of $0.004 \% \mathrm{DPPH}$ solution was added with various concentrations (15.625 to $500 \mu \mathrm{g} / \mathrm{mL})$ of crude extract, while a methanol plus DPPH solution was used as a negative control. The mixed solutions were then incubated for half an hour at a $30^{\circ} \mathrm{C}$ temperature in a darkened room. A UV spectrophotometer was used to measure the absorbance at $517 \mathrm{~nm}$. The reduction of absorbance with a high concentration implies effective radical scavenging activity. As a reference standard, ascorbic acid was applied [26]. The inhibition percentage of free radicals was measured by the following Equation (1):

$$
\% \text { Scavenging activity }=\frac{\mathrm{Ac}-\mathrm{As}}{\mathrm{Ac}} \times 100,
$$

where Ac is the absorbance of the control and As is the absorbance of the sample.

\subsubsection{Power Reduction Assay}

Reduction of the power capacity of MELHS was evaluated by following the method of Oyaizu [27]. About $1 \mathrm{~mL}$ of serially diluted concentration $(31.25$ to $500 \mu \mathrm{g} / \mathrm{mL})$ was mixed with $2.5 \mathrm{~mL}$ of phosphate buffer $(0.2 \mathrm{M}, \mathrm{pH} 6.6)$ and potassium ferricyanide $(1 \% w / v)$. The mixed solution was incubated for $20 \mathrm{~min}$ at a $50{ }^{\circ} \mathrm{C}$ temperature to complete the reaction. After incubation, $2.5 \mathrm{~mL}$ of trichloroacetic acid $(10 \%)$ was added and the whole mixture was centrifuged for $10 \mathrm{~min}$ at $3000 \mathrm{RPM}$. After that, the supernatant solution was dispelled and $0.5 \mathrm{~mL}$ of ferric chloride $(0.1 \% w / v)$ was added to the solution with $2.5 \mathrm{~mL}$ of distilled water gradually mixed in. Therefore, the absorbance of the mixer was investigated on a UV spectrophotometer at $700 \mathrm{~nm}$. A phosphate buffer was used as a blank solution, while ascorbic acid was used as a reference standard. 


\subsubsection{Total Phenolic Content}

The total phenolic content (TPC) of MELHS was investigated by the method of Singleton et al. as an oxidizing agent, and Folin-Ciocalteu reagent (FCR) was applied [28]. Two and a half milliliters of sodium carbonate $(20 \%)$ was mixed with $2.5 \mathrm{~mL}$ of FCR, which was diluted 10 times with water. Then, a $500 \mu \mathrm{g} / \mathrm{mL}$ extract was combined with the mixture. After that, distilled water was added to the mixed solution to make up a $10 \mathrm{~mL}$ solution and kept in incubation for $20 \mathrm{~min}$ at a $25^{\circ} \mathrm{C}$ temperature to react effectively. The absorbance of the sample was taken at $760 \mathrm{~nm}$ on the UV spectrophotometer. TPC was calculated from a calibration curve using a standard gallic acid solution of several concentrations, whereas the absorbance value plotted against concentrations and the results was assessed in $\mathrm{mg}$ gallic acid equivalent concentrations.

\subsubsection{Total Flavonoid Content}

The total flavonoid content of MELHS was determined by the colorimetric method described by Chang et al., whereas quercetin was used as a reference standard [29]. About $100 \mu \mathrm{L}$ of aluminum chloride (10\%) and $1.5 \mathrm{~mL}$ of methanol were mixed with a $500 \mu \mathrm{g} / \mathrm{mL}$ extract solution. Afterward, $100 \mu \mathrm{L}$ of potassium acetate $(1 \mathrm{M})$ and $2.8 \mathrm{~mL}$ of distilled water were mixed into the solution. The mixed solution was incubated for half an hour at room temperature $\left(37^{\circ} \mathrm{C}\right)$ so that the mixture reaction could be completed. A UV spectrophotometer was used to measure the absorbance of the mixed solution at 415 $\mathrm{nm}$ against the blank solution, which contained all the reagents except the extract. The calibration curve was developed by employing several quercetin concentrations and the total flavonoid content was assessed in $\mathrm{mg} / \mathrm{g}$ of quercetin equivalent.

\subsection{Brine Shrimp Lethality Bioassay}

Brine shrimp eggs (Artemia salina leach) were used as a test organism to inspect the toxic properties of the extract. Shrimp eggs were hatched in artificial seawater, which was developed using sea salt $(38 \mathrm{~g} / \mathrm{L})$, with $\mathrm{NaOH}(1 \mathrm{~N})$ added to adjust the $\mathrm{pH}$ to 8.5 , and then placed at room temperature $\left(37^{\circ} \mathrm{C}\right)$ with a constant oxygen supply. After that, the hatched eggs were allowed to mature for $48 \mathrm{~h}$ and shrimp larvae known as nauplii were obtained. The procedure of the cytotoxic bioassay was performed according to the method of Meyer et al. [30]. The plant extract was dissolved in DMSO $(5 \mathrm{mg} / \mathrm{mL})$ to make a test sample with artificial seawater. Through serial dilution, several concentrations (31.25 to $1000 \mu / \mathrm{mL})$ were obtained. Vincristine sulfate was used as a positive control, also using serial dilution to obtain different concentrations from 0.125 to $10 \mu \mathrm{g} / \mathrm{mL}$, as in the preceding method. Ten living nauplii were added to the experimental vials and control vials and incubated for one day under light at room temperature. An amplifying glass was used to inspect all vials so that the numbers of living nauplii could be calculated and recorded for each vial. The mortality percentage of nauplii was calculated using Equation (2):

$$
\text { Percentage }(\%) \text { of mortality }=\frac{\mathrm{N}_{0}-\mathrm{N}_{1}}{\mathrm{~N}_{0}} \times 100,
$$

where $\mathrm{N}_{0}$ is the number of nauplii taken and $\mathrm{N}_{1}$ is the number of nauplii alive.

\subsection{In Vitro Thrombolytic Activity}

The thrombolytic activity of MELHS was explored using the method previously described by Prasad et al. [31]. As a stock solution, a vial of lyophilized streptokinase $(1,500,000$ I.U.) was diluted with $5 \mathrm{~mL}$ of sterile distilled water. Five milliliters of venous blood was drawn from six volunteers who were healthy and had no history of anticoagulant therapy. After that, the blood was distributed among six different pre-weighed sterile microcentrifuge tubes in the amount of $0.5 \mathrm{~mL} /$ tube and incubated at $37^{\circ} \mathrm{C}$ for $45 \mathrm{~min}$. After clot enhancement, the serum was carefully removed without disturbing the clot formation, which was weighed once again. A volume of $100 \mu \mathrm{L}(10 \mathrm{mg} / \mathrm{mL})$ of plant extract was added to each tube. Then, distilled water $(100 \mu \mathrm{L})$ and streptokinase $(100 \mu \mathrm{L})$ 
were separately added to the negative (non-thrombolytic) and positive control group, respectively, whereas water was used as a negative control. After this, all the tubes were incubated again for one and a half hours at $37^{\circ} \mathrm{C}$. Finally, the released fluid was cleaned and all tubes were weighed once again to calculate the weight difference after clot disruption. The percentage of clot lysis was calculated using Formula (3):

$\%$ clot lysis $=($ weight of clot after removing the fluid $/$ weight of clot $) \times 100$.

This human-related experiment was conducted according to the ethical standards laid down in the 1964 Declaration of Helsinki. This study protocol was approved by the Department of Pharmacy, International Islamic University Chittagong, Chittagong, Bangladesh (ref. number: IIUC/PHARM-AEC-150/20-2019).

\subsection{In Vivo Pharmacological Activity}

\subsubsection{Experimental Animals and Ethical Statement}

All animal experiments were carried out at the Department of Pharmacy, International Islamic University Chittagong, Chittagong-4318, Bangladesh. Male and female Swiss albino mice weighing around 25-30 g were purchased from Jahangirnagar University, Savar-1342, Bangladesh. The animals were housed in polypropylene cages $(120 \times 30 \times 30 \mathrm{~cm})$ and kept in standard conditions $\left(25 \pm 2{ }^{\circ} \mathrm{C}, 55-60 \%\right.$ relative humidity, and $12 \mathrm{~h}$ light/dark circle) with a supply of water and food pellets. All mice were acclimated for 14 days to adapt to laboratory conditions before the experiments were started. Every effort was made to minimize the suffering of the animals. At the end of the observation period, all mice were euthanized using diethyl ether anesthesia. All the protocols followed in this experiment were approved by the Institutional Animal Ethical Committee, Department of Pharmacy, International Islamic University Chittagong, Chittagong-4318, Bangladesh, according to government guidelines under the reference number IIUC/PHARM-AEC150/20-2019 [32]. All the sections of this report adhere to the "Animal Research: Reporting of In Vivo Experiments" guidelines for reporting animal research. The "Principles of the Laboratory Animal Care" (NIH publication no. 85-23, revised 1985) and "National Animal Care Laws" were strictly followed during the handling of the animals in this study.

\subsubsection{Experimental Design}

The experimental animals were randomly separated into four different groups (standard, control, and test groups), with six Swiss albino mice included in each group. MELHS was administered to the test groups at two different dosages ( 200 and $400 \mathrm{mg} / \mathrm{kg}$, b.w, p.o., respectively) and the vehicle ( $1 \%$ Tween- 80 in water) was administered to the control group at a dosage of $10 \mathrm{~mL} / \mathrm{kg}$ (p.o.). Standard Fluoxetine $(20 \mathrm{mg} / \mathrm{kg})$ was given intraperitoneally for the tail suspension test (TST) and forced swimming test (FST), while the drug diazepam $(1 \mathrm{mg} / \mathrm{kg}$, b.w, i.p.) was treated as standard for the elevated plus maze test (EPM). The plant extract doses and vehicle were received half an hour before the experiment and the reference drugs $15 \mathrm{~min}$ before the experiment.

\subsubsection{Acute Oral Toxicity Test}

The acute oral toxicity test was carried out according to the "OECD Guidelines" [33]. Several doses of methanol extract $(500,1000,2000$, and $4000 \mathrm{mg} / \mathrm{kg}$ ) were given orally to six Swiss albino mice who had fasted for $18 \mathrm{~h}$ before the administration of the doses. The mice were investigated individually for unusual signs, including allergic syndrome (itching, skin rash, swelling, etc.) and mortality within $72 \mathrm{~h}$.

\subsubsection{Anxiolytic Activity \\ Elevated Plus Maze Test}

The elevated plus maze test was used to screen the activity of the anxiolytic properties of MELHS in mice [34]. The experiment was carried out in a sound-attenuated room. The equipment used in this experiment consisted of four arms, with two open arms $(5 \times 10 \mathrm{~cm})$ 
and two closed arms $(5 \times 10 \times 15 \mathrm{~cm})$ combined on a focal point platform $(5 \times 5 \mathrm{~cm})$ in a plus sign configuration. All the groups of mice were administered different doses, as described in Section 2.9.2. Half an hour after the administration of the doses, a single animal from one of the four different groups was placed at the pivotal point of the platform facing the closed arm and allowed to roam for five minutes. An animal which placed all four of its paws onto any arm was recorded as having entered the arm. The total number of entries in the different types of arm (closed or open) and the times spent there were recorded. At the end of the experiment, the mice were euthanized using diethyl ether anesthesia. The percentage of entries into the open arm was calculated using Formula (4):

$\%$ of entries in open arm $=\frac{\text { Number of entries in open arm }}{\text { Number of entries open arm }+ \text { Number of entries close arm }} \times 100$.

\subsubsection{Antidepressant Activity \\ Tail Suspension Test}

The tail suspension test was carried out following the method of Steru et al. [35]. All groups of mice were given different doses, as described in Section 2.9.2. Mice from each of the groups were individually suspended for six minutes in a box $(25 \times 25 \times 30 \mathrm{~cm})$, held by adhesive tape attached to the ends of their tails. Their total time of immobility was documented during the final four minutes of the six-minute suspension. The experiment was carried out with minimal ambient noise.

\section{Forced Swimming Test}

The forced swimming test was conducted using the method of Porsolt et al. [36] to investigate the in vivo antidepressant activity. The experiment was divided into two sessions: The first was carried out the day before the second to enable the animals to adapt to the environment. Immobility was created by placing the mice in a transparent glass tank $(25 \times 15 \times 25 \mathrm{~cm})$ filled with $15 \mathrm{~cm}$ of water at room temperature. Control, standard, and test group mice were treated with doses as described in Section 2.9.2. Each mouse was placed in the tank half an hour after the dose had been administered, and was allowed to swim around for six minutes. The first two minutes were regarded as a preliminary adjustment time. The final four minutes were used for measuring immobility.

\subsection{Statistical Analysis}

SPSS software was used for data analysis and GraphPad Prism version 6.0 was used to draw the figures. The results are presented as the mean \pm SEM (standard error mean), and $p$ values of less than $0.05,0.01$, and 0.001 were considered statistically significant (Dunnett's multiple comparison test).

\section{Results}

\subsection{Qualitative Phytochemical Investigation}

Qualitative phytochemical experiments were conducted for the L. hyalina stem extract to expose the presence of alkaloid, carbohydrate, reducing sugar, flavonoid, saponin, tannin, unsaturated sterol, triterpene, phenol, quinone, cardiac glycoside, and coumarin. The output of the various biochemical tests is summarized in Table 1 below. 
Table 1. Result of the phytochemical screening of Lepidagathis hyalina Nees stems.

\begin{tabular}{cccc}
\hline Phytochemicals & Type of Test & Appearance & Results \\
\hline Alkaloids & Mayer's test & Yellow color & ++ \\
Carbohydrates & Wagner test & A reddish brown color & ++ \\
Glycosides & Molisch's test & Reddish color ring form & ++ \\
Reducing sugar & Shinoda test & No deep red color & - \\
Flavonoids & Fehling's test & Red precipitate form & ++ \\
Saponins & Benedict's test & Reddish color precipitate form & ++ \\
Tannin & Lead acetate test & Florescence yellow color form & ++ \\
Sterols & Froth test & Persistent forth for one hour & + \\
Triterpene & FeCl test & Brownish green appears & + \\
Resin & Liebermann-Burchard test & No layer form & - \\
Phenol & Salkowski test & Reddish color form & + \\
Quinones & FeCl test & No precipitation & - \\
Cardiac Glycoside & FeCl $_{3}$ test & Violet color form & ++ \\
Coumarins & HCl test & Yellow color present & + \\
Cholesterols & Legal test & Brown color & + \\
Terpenoids & Ammonia test & Green color form & ++ \\
\hline
\end{tabular}

Here, ++ , highly present; +, moderately present; and -, absent.

\subsection{Antioxidant Activity}

\subsubsection{DPPH Scavenging Activity}

Through the DPPH free radical scavenging qualitative assay, the antioxidant properties of MELHS were estimated. Figure 1 demonstrates that MELHS has a good antioxidant potency compared with the standard application of ascorbic acid. As can be seen, the scavenging capacity increased compared with the increased concentration of ascorbic acid. The sample extract exhibited a maximum scavenging capacity $(85.52 \%)$ at a $500 \mu \mathrm{g} / \mathrm{mL}$ concentration, while the standard demonstrated a maximum scavenging capacity of $97.05 \%$ at the same concentration. The $\mathrm{IC}_{50}$ values for ascorbic acid and MELHS (5.93 and $125.16 \mu \mathrm{g} / \mathrm{mL}$, respectively) were estimated via the linear regression equation. Here, the linear regression equation was $y=0.1518 x+28.697$, with a correlation coefficient $\left(R^{2}\right)$ of 0.8278 .

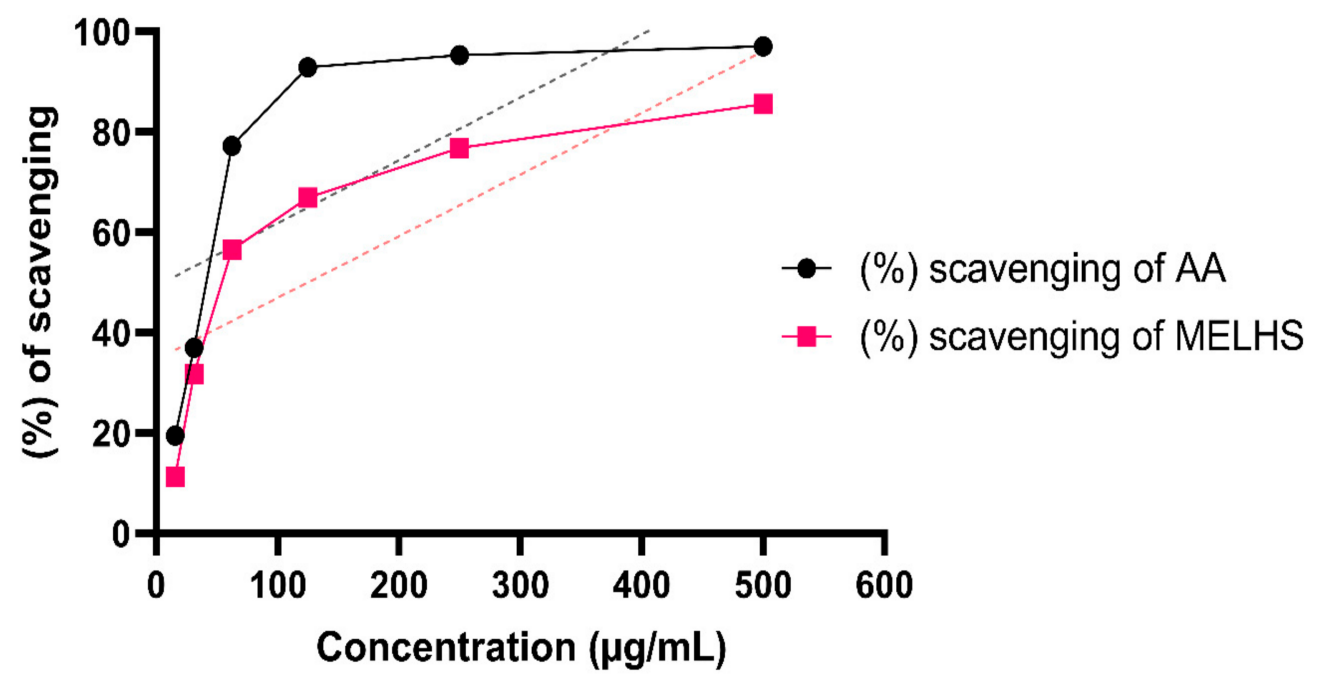

Figure 1. Percentage of radical scavenging activities exhibited by the 1,1-diphenyl-2-picrylhydrazyl (DPPH) assay of the methanol extract of L. hyalina stems (MELHS) and standard drug ascorbic acid (AA) at different concentrations. 


\subsubsection{Reducing Power Assay}

An antioxidant ability assessment test is summarized in Figure 2 for different doses of ascorbic acid and MELHS. It can be seen that, as the mass concentrations of extracts increase, so does the reducing power of both the standard and sample extracts. The highest absorbance of MELHS was 0.568 at a $1000 \mu \mathrm{g} / \mathrm{mL}$ concentration, whereas at the same density, the absorbance of ascorbic acid was 1.88 .

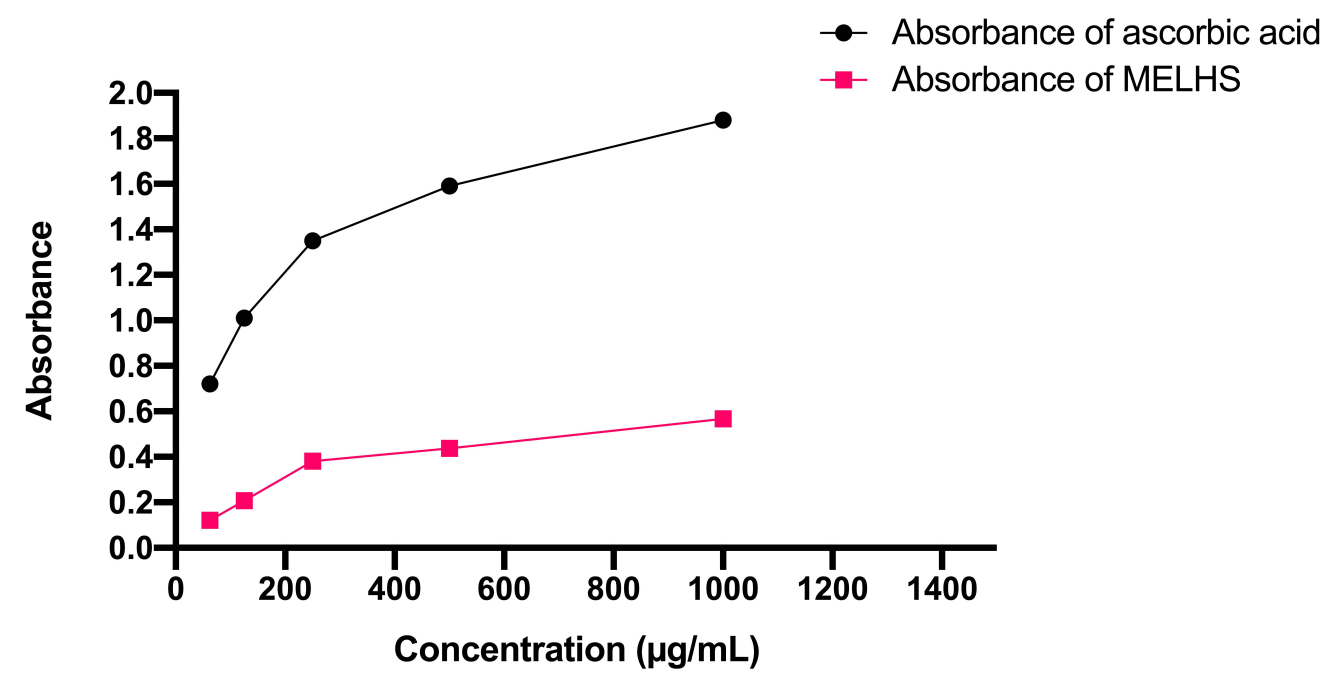

Figure 2. Reducing power of MELHS and standard drug ascorbic acid (AA) at different concentrations.

\subsubsection{Total Phenolic and Flavonoid Contents}

A quantitative study of the antioxidant-related total phenolic and flavonoid content of MELHS was carried out using a regression equation (for total phenolic, the regression equation was $y=0.0039 x+0.033$ and for flavonoid, it was $y=0.0102 x-0.0637$ ). The total antioxidant-related phenolic and flavonoid contents of MELHS were $150.96 \pm 1.04 \mathrm{mg}$ $\mathrm{GAE} / \mathrm{g} \mathrm{LH}$ and $47.32 \pm 0.77 \mathrm{mg} \mathrm{QE} / \mathrm{g} \mathrm{LH}$, respectively.

\subsection{Cytotoxic Activity}

A brine shrimp cytotoxic assay was conducted to evaluate the cytotoxic potency of MELHS. Figure 3 shows the fatality percentages, as well as the $\mathrm{LC}_{50}(115.11 \mu \mathrm{g} / \mathrm{mL})$ value derived using the equation. The average percentage was found to be $61.43 \%$ in a dosedependent model. A $100 \%$ mortality rate was observed for a $1000 \mu \mathrm{g} / \mathrm{mL}$ concentration of sample extract, while a $30 \%$ mortality rate was observed for a $15.625 \mu \mathrm{g} / \mathrm{mL}$ concentration.

\subsection{Thrombolytic Activity}

The thrombolytic activity and health status of an adult volunteer are shown in Figure 4. The application of MELHS resulted in a reasonable thrombolytic ability: A $10 \mathrm{mg} / \mathrm{mL}$ concentration of sample extract exhibited a 33.98\% clot-lysis capability, whereas the positive control (streptokinase) demonstrated a 75\% clot-lysis capability. However, the negative control (normal saline) exhibited low clot-lysis capability (4.84\%).

\subsection{Acute Oral Toxicity Test}

No behavioral change or mortality was observed during the observation period of $72 \mathrm{~h}$. As a result, a dose of MELHS of up to $2000 \mathrm{mg} / \mathrm{kg}$ was recorded as being safe. 


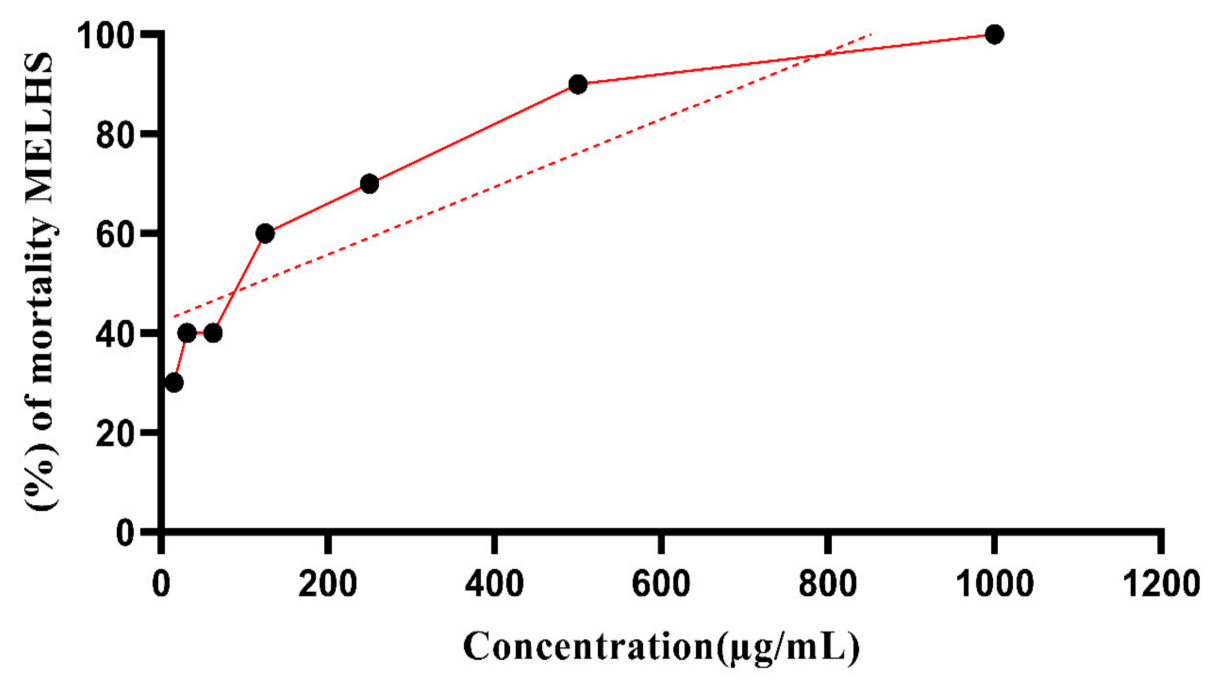

Figure 3. Percentage of mortality of brine shrimp at different concentrations of MELHS.

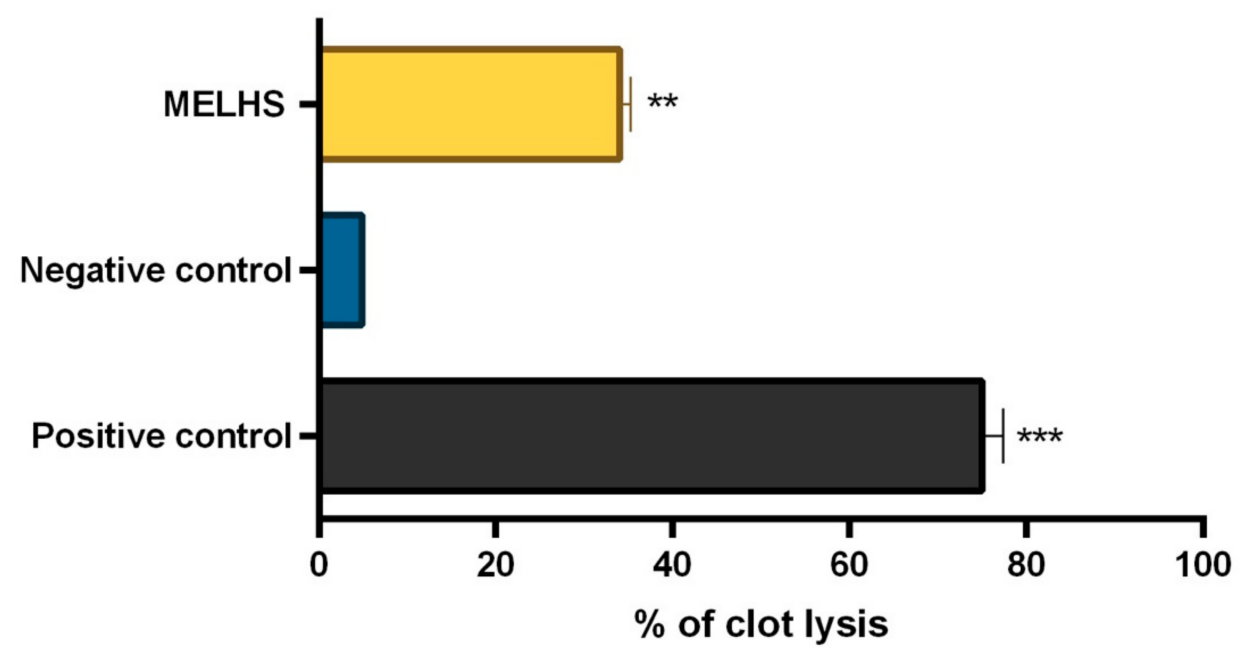

Figure 4. Percentage of clot lysis of MELHS. The results are expressed as the mean \pm SEM, where ** $p<0.01$ and ${ }^{* * *} p<0.001$ are considered statistically significant. The statistical analysis followed by one-way analysis of variance (Dunnett's test) compared to the negative control ( $1 \%$ Tween- 80$)$ using GraphPad Prism version 6.0.

\subsection{Anxiolytic Activity \\ Elevated Plus Maze (EPM)}

This experiment was conducted to evaluate the anti-anxiety potency of MELHS. The use of MELHS in animals showed promising results. It significantly increased the number of entries into the open arms, as well as the time spent in the open arms, as shown in Figure 5. For the oral $200 \mathrm{mg} / \mathrm{kg}$ dose, the percentage of entries into the open arms and the time spent in the open arms were $60.84 \pm 4.05$ and $66.50 \pm 3.14$, respectively. In contrast, for the $400 \mathrm{mg} / \mathrm{kg}$ dose, the percentage of entries into the open arms and the time spent in the open arms were $73.89 \pm 5.97$ and $78.77 \pm 4.42(p<0.05)$, respectively. For the control dose $(10 \mathrm{~mL} / \mathrm{kg})$, the percentage of entries into the open arms and the time spent in the open arms were $53.86 \pm 1.84$ and $56.02 \pm 1.48$, respectively. The diazepam $(1 \mathrm{mg} / \mathrm{kg})$ treatment also significantly increased the percentage of entries into the open arm and the time spent in the open arms, producing values of $87.02 \pm 2.08$ and $94.03 \pm 3.63(p<0.01)$, respectively. 


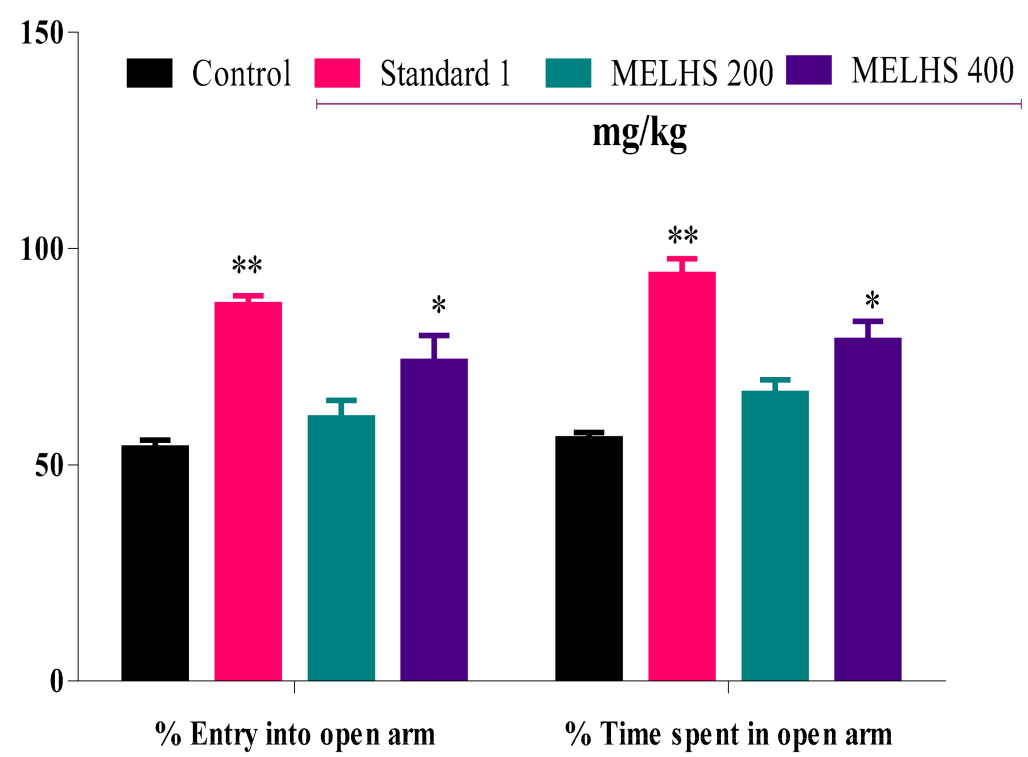

Figure 5. Exploration of the anxiolytic behavior of MELHS and diazepam (standard) in an elevated plus-maze test. The results are expressed as the mean $\pm \mathrm{SEM}$, where ${ }^{*} p<0.05$ and ${ }^{* *} p<0.01$ are considered statistically significant. The statistical analysis followed by one-way analysis of variance (Dunnett's test) compared to the negative control (1\% Tween-80) using GraphPad Prism version 6.0.

\subsection{Antidepressant Activity}

\subsubsection{Tail Suspension Test}

In this anti-depression study, the applied dose of MELHS exhibited noteworthy results compared with the standard drug, as shown in Figure 6. The methanol extract showed a dose-dependence tendency. The immobile time of the experimental mice decreased from $123.67 \pm 4.26(33.51 \%)$ to $87.67 \pm 6.40 \mathrm{~s}(52.88 \%)$ as the doses were increased from 200 to $400 \mathrm{mg} / \mathrm{kg}$, respectively. Both doses presented significant results $(p<0.01)$ compared with the control $(186 \pm 1.69)$. The immobile time of fluoxetine $(20 \mathrm{mg} / \mathrm{kg})$ was $82.33 \pm 1.18 \mathrm{~s}$ $(55.73 \%)$, which was also significant compared with the control $(p<0.001)$.

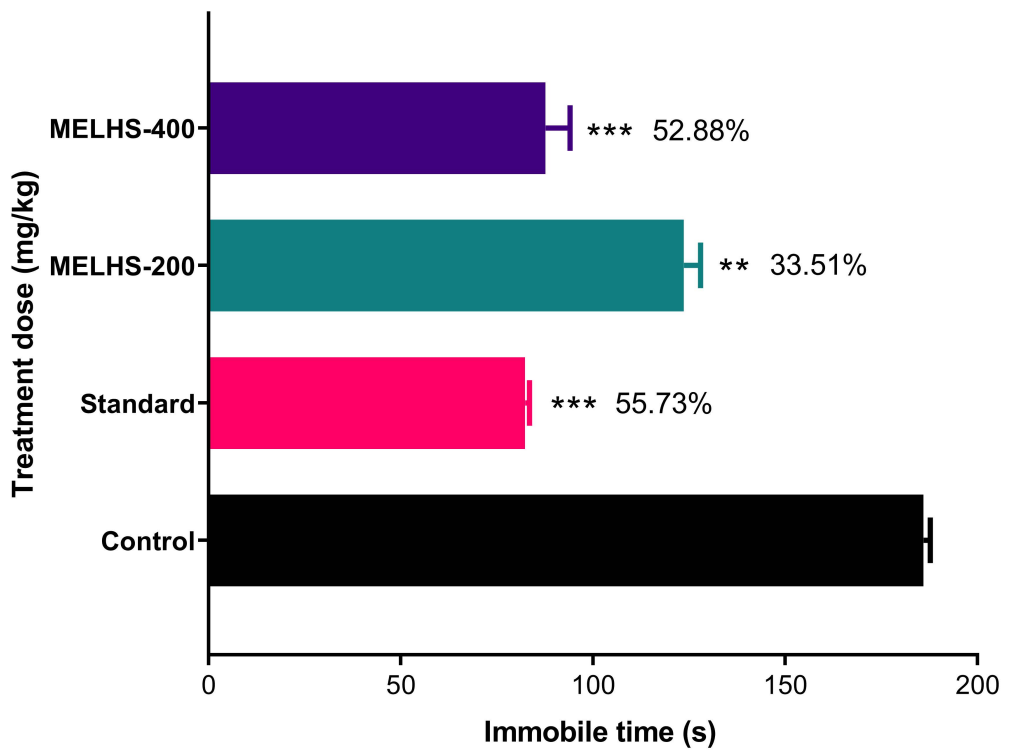

Figure 6. Exploration of the antidepressant activity of MELHS in a tail suspension test in mice. The results are expressed as the mean \pm SEM, where ${ }^{* *} p<0.01$ and ${ }^{* *} p<0.001$ are considered statistically significant. The statistical analysis followed by one-way analysis of variance (Dunnett's test) compared to the negative control (1\% Tween-80) using GraphPad Prism version 6.0. 


\subsubsection{Forced Swimming Test}

The methanol extract revealed anti-depressant-like bioactivity in mice in the forced swimming tests shown in Figure 7. Showing a dose-dependence tendency, the extract at 200 and $400 \mathrm{mg} / \mathrm{kg}$ significantly decreased the immobility time to $114 \pm 4.36(41.44 \%)$ and $83.33 \pm 6.39 \mathrm{~s}(57.20 \%)$, respectively, in comparison with the control group (194.67 $\pm 2.91 \mathrm{~s})$ $(p<0.01)$. The immobility time for the reference drug fluoxetine $(20 \mathrm{mg} / \mathrm{kg})$ also significantly reduced the immobility time to $88 \pm 1.15 \mathrm{~s}(54.80 \%),(p<0.001)$.

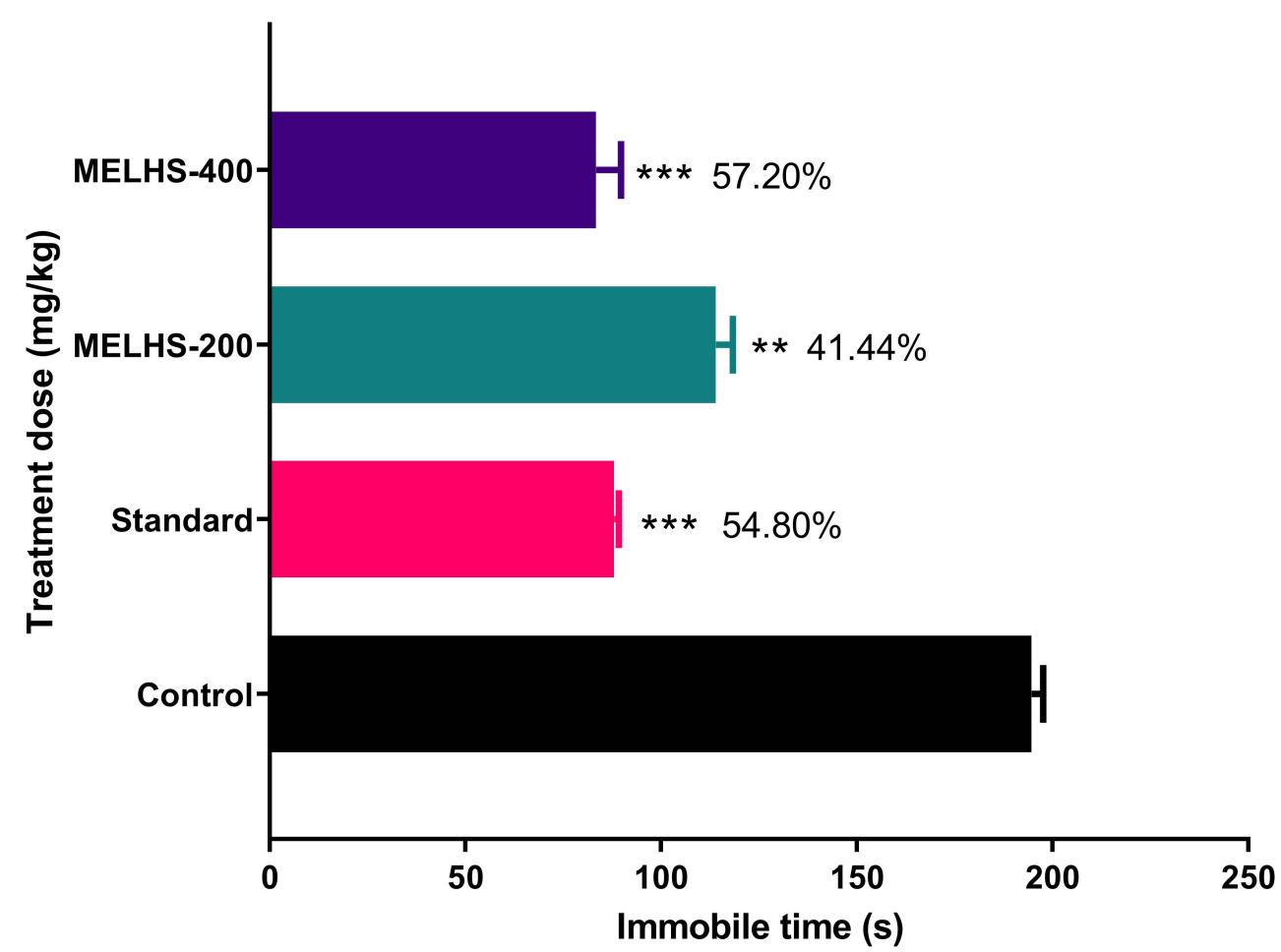

Figure 7. Exploration of the antidepressant activity of MELHS in a forced swimming test in mice. The results are expressed as the mean \pm SEM, where ${ }^{* *} p<0.01$ and ${ }^{* * *} p<0.001$ are considered statistically significant. The statistical analysis followed by one-way analysis of variance (Dunnett's test) compared to the negative control (1\% Tween-80) using GraphPad Prism version 6.0.

\section{Discussion}

Medicinal plants play a significant role in medical science by modulating various human dysfunctions. From the beginning of civilization, human beings have depended on medicinal plants for curing their bodily disorders. As a potential source of biologically active compounds, medicinal plants may definitely be considered superior $[37,38]$. They have traditionally been used for curing various kinds of diseases [39]. Several chemicals derived from plants serve as medicinal agents, offering a range of biological activity: Antioxidant, cytotoxicity, thrombolytic, anxiolytic, antidepressant, neuroprotective, hepatoprotective, etc. [40-45]. In qualitative and quantitative phytochemical analyses, MELHS has demonstrated various types of phytochemical groups. The phytochemical analysis in this study confirmed the presence of alkaloids, carbohydrates, flavonoids, saponin, tannin, triterpene, phenol, quinone, cardiac glycoside, and coumarin, as well as an extensive range of polyphenolic compounds (Table 1). It might therefore be possible that such phytochemicals were responsible for the DPPH scavenging activity and ferric-reducing capacity of the MELHS plant extract [46-51].

The brine shrimp lethality bioassay is a more suitable method for observing the biological properties of natural products [52]. It is a fast, cheap, and simple biological assay for evaluating the plant extract toxicity, which in many cases, connects reasonably with cytotoxic and antitumor or anticancer activities $[53,54]$. In this experiment, the brine shrimp 
bioassay was used to estimate the lethality of crude extracts of MELHS. An estimation of the toxicity of plant extracts is obligatory when determining their safety as a treatment, in order to detect both the inherent toxicity of the plant and the outcome of an acute overdose. This study has helped gauge the biological reaction to the natural plant extract $[55,56]$. Furthermore, it has helped to established the dosages that can be administered to animal models [57]. In the calculation of the overall toxicity using brine shrimp, the maximum fatality occurred at a $1000 \mu \mathrm{g} / \mathrm{mL}$ concentration, while the minimum fatality occurred at a $10 \mu \mathrm{g} / \mathrm{mL}$ concentration. The cytotoxic properties were measured as weak in the range $500 \geq \mathrm{LC}_{50} \leq 1000 \mu \mathrm{g} / \mathrm{mL}$, moderate in the range $100 \geq \mathrm{LC}_{50} \leq 500 \mu \mathrm{g} / \mathrm{mL}$, strong in the range $0>\mathrm{LC}_{50}<100 \mu \mathrm{g} / \mathrm{mL}$, and nontoxic in the ranged $\mathrm{LC}_{50}>1000 \mu \mathrm{g} / \mathrm{mL}$ [58]. In this study, the rate of mortality was directly proportional to the concentration of the plant extract of MELHS, with $\mathrm{LC}_{50}$ of $115.11 \mu \mathrm{g} / \mathrm{mL}$, which is moderately cytotoxic. The cytotoxic bioactivity of MELHS may be due to the existence of anti-tumor components, as well as the presence of flavonoid contents, in the MELHS plant extract [59].

Thrombolysis is the dissolution of hazardous clots in blood vessels for promoting blood flow and averting injury to tissues and organs [60]. This blood accumulation leads to an internal hemorrhage, which may threaten vital organs such as the brain, heart, kidneys, etc. Thrombolytic agents such as streptokinase are used to dissolve blood clots [61]. Generally, to liquefy blood coagulates, a thrombolytic mediator triggers the plasminogen that forms plasmin, which acts as a cleavage factor [62-64]. This is a proteolytic enzyme that is capable of preventing cross-links between fibrin particles. Various plant sources such as herbs, leaves, fruits, and seed may have anti-clot, anti-platelet, and fibrinolytic bio-properties. In this study, it was found that the capacity for the clot lysis of MELHS was $33.98 \%(p<0.01)$ at a $10 \mathrm{mg} / \mathrm{mL}$ concentration, which was significant compared with the negative control, while the streptokinase and negative control (normal saline) showed a capability for clot lysis of $75 \%$ and $4.84 \%$, respectively. The thrombolytic properties of MELHS may arise from the presence of flavonoids in the methanol extract [60].

The elevated plus-maze (EPM) test is a behavioral experiment used to measure anxiety in mice, based on the animals' aversion to open spaces. In this study, entry into open arms and closed arms was available to the mice. In the EPM test, the plant extract's anxiolytic activity caused a greater number of entries and more time spent in open arms than in closed arms [61]. Moreover, the $400 \mathrm{mg} / \mathrm{kg}$ dose significantly increased the percentage of entries into open arms and the time spent in open arms to $73.89 \pm 5.97$ and $78.77 \pm 4.42$ $(p<0.05)$, respectively. For the standard candidate (diazepam), the respective percentages were $87.02 \pm 2.08$ and $94.03 \pm 3.63(p<0.01)$. MELHS can therefore be said to produce a significant anxiolytic effect, probably due to the presence of phenolic compounds $[62,63]$.

Depression is a mood-altering disorder. Its symptoms include feelings of sadness, loss, or anger that interfere with a person's everyday activities. Its many causes include stress, long-term anxiety, and several chronic disorders [64-67]. It has also been reported that depressed people have increased oxidative stress and reduced anti-oxidant defenses [68]. To investigate the antidepressant properties of MELHS, the current study conducted forced swimming and tail suspension tests. In these tests, mice were compelled to swim in water or allowed to hang by their tails, in each case creating a situation of despair. In such cases, lower immobility times indicate higher rates of anti-depressant activity $[69,70]$. In TST and FST, the maximum immobility times of mice were $87.67 \pm 6.40 \mathrm{~s}(52.88 \%),(p<0.001)$ and $83.33 \pm 6.39 \mathrm{~s}(57.20 \%),(p<0.001)$, respectively, for a $400 \mathrm{mg} / \mathrm{kg}$ oral dose, against the positive control ( $20 \mathrm{mg} / \mathrm{kg}$ fluoxetine), whose immobility times were $82.33 \pm 1.18 \mathrm{~s}$ (55.73\%), (in TST) and $88 \pm 1.15 \mathrm{~s}(54.80 \%),(p<0.001)$ (in FST). The anti-depressant results of MELHS are therefore close to the values for the standard drug, indicating very good anti-depressant activity. A number of previous studies have suggested that the presence of total phenols and flavonoids may be responsible for this antidepressant effect [71,72]. 


\title{
5. Conclusions
}

The collected pharmacological findings indicate the strong potential of this plant. This study reveals that the extract is a potential source of antioxidants. It also argues that MELHS offers noteworthy thrombolytic activity and moderate cytotoxic activity. Additionally, the plant extract may have potential applications in the treatment of psychiatric conditions such as anxiety and depression, probably due to the presence of phenol and flavonoids in the plant extract. Overall, this plant can be recognized as a possible candidate for the creation of a new drug compound with numerous pharmacological applications. Further extensive studies are still required to identify the secondary metabolites of the plant responsible for the biological activities observed, and also to determine the mechanism behind its therapeutic activities.

Author Contributions: F.I.F. and N.B. investigated, planned, and designed the research. M.A.S. arranged the facilities for the experimental research and supervised the research. F.I.F., N.B., M.S.I., M.N.I., K.B. and M.J.U. prepared the extract, and carried out experimental work, data collection, evaluation, and the literature search. F.I.F., N.B. and S.A.J.S. contributed to the study design and interpreted the results, working on statistical analysis with M.A.S. F.I.F., N.B., S.A.J.S., M.N.U.C., M.A., E.P. and M.A.S. participated in the manuscript draft and thoroughly checked and revised the manuscript for necessary changes in the format. M.A.S., T.B.E., J.S.-G. and R.C. supervised the entire research work. All authors have read and agreed to the published version of the manuscript.

Funding: This work was conducted with the individual funding of all authors.

Institutional Review Board Statement: All the experimental protocols were assessed and approved by the Institutional Animal Ethical Committee, Department of Pharmacy, International Islamic University Chittagong, Chittagong-4318, Bangladesh, under the reference number of IIUC/PHARMAEC-150/20-2019. This human-related experiment was conducted according to the ethical standards laid down in the 1964 Declaration of Helsinki.

Informed Consent Statement: Not applicable.

Data Availability Statement: Available data are presented in the manuscript.

Acknowledgments: The authors are thankful to the Department of Pharmacy, International Islamic University Chittagong (IIUC), Bangladesh for research facilities and other logistical support. The authors are also thankful to Shaikh Bokhtear Uddin for identifying the plant. The authors would like to thank Cambridge Proofreading \& Editing LLC. for editing a draft of this manuscript.

Conflicts of Interest: The authors declare that they have no conflict of interest.

\begin{abstract}
Abbreviations
MELHS, methanol extract of Lepidagathis hylina Nees stems; DPPH, 1,1-diphenyl-2-picrylhydrazyl; FCR, Folin-Ciocalteau reagent; UV, ultra-violet; BW, body weight; TPC, total phenol content; TFC, total flavonoid content; EPM, elevated plus maze; TST, tail suspension test; FST, forced swimming test; SEM, standard error mean; p.o., per oral; i.p., intraperitoneal.
\end{abstract}

\section{References}

1. Uttara, B.; Singh, A.V.; Zamboni, P.; Mahajan, R. Oxidative stress and neurodegenerative diseases: A review of upstream and downstream antioxidant therapeutic options. Curr. Neuropharmacol. 2009, 7, 65-74. [CrossRef] [PubMed]

2. Aziz, M.A.I.N.; Barua, N.; Tareq, A.M.; Alam, N.; Prova, R.J.; Mamun, M.N.; Sayeed, M.A.; Chowdhury, M.A.U.; Emran, T.B. Possible neuropharmacological effects of Adenia trilobata (Roxb.) in the Swiss Albino mice model. Future J. Pharm. Sci. 2020, 6, 1-8.

3. Nicolini, F.A.; Nichols, W.W.; Mehta, J.L.; Saldeen, T.G.; Schofield, R.; Ross, M.; Player, D.W.; Pohl, G.B.; Mattsson, C. Sustained reflow in dogs with coronary thrombosis with K2P, a novel mutant of tissue-plasminogen activator. J. Am. Coll. Cardiol. 1992, 20, 228-235. [CrossRef]

4. World Health Organization. The World Health Report 2001: Mental Health: New Understanding, New Hope; World Health Organization: Geneva, Switzerland, 2001.

5. Reynolds, E. Brain and mind: A challenge for WHO. Lancet 2003, 9373, 1924-1925. [CrossRef]

6. Thase, M.E.; Howland, R.H. Biological processes in depression: An updated review and integration. In Handbook of Depression; Guilford Press: New York, NY, USA, 1995. 
7. World Health Organization. Depression and Other Common Mental Disorders: Global Health Estimates; World Health Organization: Geneva, Switzerland, 2017; pp. 1-24.

8. Beck, A.T.; Beamesderfer, A. Assessment of depression: The depression inventory. In Psychological Measurements in Psychopharmacology; Karger Publishers: Basel, Switzerland, 1974; Volume 7, pp. 151-169.

9. Barlow, D.H. Anxiety and Its Disorders: The Nature and Treatment of Anxiety and Panic; Guilford Press: New York, NY, USA, 2004.

10. Berton, O.; Nestler, E.J. New approaches to antidepressant drug discovery: Beyond monoamines. Nat. Rev. Neurosci. 2006, 7, 137-151. [CrossRef] [PubMed]

11. Alam, S.; Emon, N.U.; Shahriar, S.; Richi, F.T.; Haque, M.R.; Islam, M.N.; Sakib, S.A.; Ganguly, A. Pharmacological and computer-aided studies provide new insights into Millettia peguensis Ali (Fabaceae). Saudi Pharm. J. 2020, 28, 1777-1790. [CrossRef] [PubMed]

12. Han, C.; Pae, C.-U. Pain and depression: A neurobiological perspective of their relationship. Psychiatry Investig. 2015, 12, 1. [CrossRef]

13. Marks, D.M.; Shah, M.J.; Patkar, A.A.; Masand, P.S.; Park, G.-Y.; Pae, C.-U. Serotonin-norepinephrine reuptake inhibitors for pain control: Premise and promise. Curr. Neuropharmacol. 2009, 7, 331-336. [CrossRef] [PubMed]

14. Hassan, W.; Barroso Silva, C.E.; Mohammadzai, I.U.; Teixeira da Rocha, J.B.; Landeira-Fernandez, J. Association of oxidative stress to the genesis of anxiety: Implications for possible therapeutic interventions. Curr. Neuropharmacol. 2014, 12, 120-139. [CrossRef]

15. Beckhauser, T.F.; Francis-Oliveira, J.; De Pasquale, R. Reactive oxygen species: Physiological and physiopathological effects on synaptic plasticity. J. Exp. Neurosci. 2016, 10, 23-48. [CrossRef] [PubMed]

16. Bakunina, N.; Pariante, C.M.; Zunszain, P.A. Immune mechanisms linked to depression via oxidative stress and neuroprogression. Immunology 2015, 144, 365-373. [CrossRef] [PubMed]

17. Penn, E.; Tracy, D.K. The drugs don't work? Antidepressants and the current and future pharmacological management of depression. Ther. Adv. Psychopharmacol. 2012, 2, 179-188. [CrossRef] [PubMed]

18. Kong, J.-M.; Goh, N.-K.; Chia, L.-S.; Chia, T.-F. Recent advances in traditional plant drugs and orchids. Acta Pharmacol. Sin. 2003, 24, 7-21. [PubMed]

19. Al Mahmud, Z.; Qais, N.; Bachar, S.C.; Hasan, C.M.; Emran, T.B.; Uddin, M.M.N. Phytochemical investigations and antioxidant potential of leaf of Leea macrophylla (Roxb.). BMC Res. Notes 2017, 10, 245. [CrossRef] [PubMed]

20. Mollik, M.; Faruque, M.; Badruddaza, M.; Chowdhury, A.; Rahman, M. Medicinal plants from Sundarbans used for the prevention of cardiovascular diseases: A pragmatic randomized ethnobotanical survey in Khulna division of Bangladesh. Eur. J. Integr. Med. 2009, 1, 231-232. [CrossRef]

21. Yadava, R. A new biologically active triterpenoid saponin from the leaves of Lepidagathis hyalina Nees. Nat. Prod. Lett. 2001, 15, 315-322. [CrossRef]

22. Rincoón, C.; Montoya, J.; Goómez, G. Optimizing the extraction of phenolic compounds from Bixa orellana L. and effect of physicochemical conditions on its antioxidant activity. J. Med. Plants Res. 2014, 8, 1333-1339.

23. Tiwari, P.; Kumar, B.; Kaur, M.; Kaur, G.; Kaur, H. Phytochemical screening and extraction: A review. Int. J. Pharm. Pharm. Sci. 2011, 1, 98-106.

24. Jahan, I.; Tona, M.R.; Sharmin, S.; Sayeed, M.A.; Tania, F.Z.; Paul, A.; Chy, M.; Uddin, N.; Rakib, A.; Emran, T.B. GC-MS phytochemical profiling, pharmacological properties, and in silico studies of Chukrasia velutina leaves: A novel source for bioactive agents. Molecules 2020, 25, 3536. [CrossRef]

25. Braca, A.; De Tommasi, N.; Di Bari, L.; Pizza, C.; Politi, M.; Morelli, I. Antioxidant principles from Bauhinia tarapotensis. J. Nat. Prod. 2001, 64, 892-895. [CrossRef] [PubMed]

26. Tareq, A.M.; Farhad, S.; Uddin, A.N.; Hoque, M.; Nasrin, M.S.; Uddin, M.M.R.; Hasan, M.; Sultana, A.; Munira, M.S.; Lyzu, C. Chemical profiles, pharmacological properties, and in silico studies provide new insights on Cycas pectinata. Heliyon 2020, 6 , e04061. [CrossRef]

27. Barua, N.; Aziz, M.A.I.; Tareq, A.M.; Sayeed, M.A.; Alam, N.; ul Alam, N.; Uddin, M.A.; Lyzu, C.; Emran, T.B. In vivo and in vitro evaluation of pharmacological activities of Adenia trilobata (Roxb.). Biochem. Biophys. Rep. 2020, 23, 100772. [CrossRef] [PubMed]

28. Singleton, V.L.; Orthofer, R.; Lamuela-Raventós, R.M. Analysis of total phenols and other oxidation substrates and antioxidants by means of Folin-Ciocalteu reagent. In Methods in Enzymology; Elsevier: Amsterdam, The Netherlands, 1999; Volume 299, pp. 152-178.

29. Chang, C.-C.; Yang, M.-H.; Wen, H.-M.; Chern, J.-C. Estimation of total flavonoid content in propolis by two complementary colorimetric methods. J. Food Drug Anal. 2002, 10, 1-3.

30. Meyer, B.; Ferrigni, N.; Putnam, J.; Jacobsen, L.; Nichols, D.J.; McLaughlin, J.L. Brine shrimp: A convenient general bioassay for active plant constituents. Planta Med. 1982, 45, 31-34. [CrossRef]

31. Prasad, S.; Kashyap, R.S.; Deopujari, J.Y.; Purohit, H.J.; Taori, G.M.; Daginawala, H.F. Development of an in vitro model to study clot lysis activity of thrombolytic drugs. Thromb. J. 2006, 4, 14. [CrossRef]

32. Zimmermann, M. Ethical guidelines for investigations of experimental pain in conscious animals. Pain 1983, 16, 109-110. [CrossRef]

33. OECD. Test No. 423: Acute Oral Toxicity-OECD Guideline for the Testing of Chemicals Section 4; OECD Publishing: Paris, France, 2002.

34. Pellow, S.; File, S.E. Anxiolytic and anxiogenic drug effects on exploratory activity in an elevated plus-maze: A novel test of anxiety in the rat. Pharmacol. Biochem. Behav. 1986, 24, 525-529. [CrossRef] 
35. Steru, L.; Chermat, R.; Thierry, B.; Simon, P. The tail suspension test: A new method for screening antidepressants in mice. Psychopharmacology 1985, 85, 367-370. [CrossRef]

36. Porsolt, R.; Bertin, A.; Jalfre, M. Behavioral despair in mice: A primary screening test for antidepressants. Arch. Int. Pharmacodyn. Ther. 1977, 229, 327.

37. Rahman, M.A.; bin Imran, T.; Islam, S. Antioxidative, antimicrobial and cytotoxic effects of the phenolics of Leea indica leaf extract. Saudi J. Biol. Sci. 2013, 20, 213-225. [CrossRef] [PubMed]

38. Shakya, A.K. Medicinal plants: Future source of new drugs. Int. J. Herb. Med. 2016, 4, 59-64.

39. Hamburger, M.; Hostettmann, K. 7. Bioactivity in plants: The link between phytochemistry and medicine. Phytochemistry 1991, 30, 3864-3874. [CrossRef]

40. Tareq, A.M.; Sohel, M.; Uddin, M.; Mahmud, M.H.; Hoque, M.; Reza, A.A.; Nasrin, M.S.; Kader, F.B.; Emran, T.B. Possible neuropharmacological effects of Apis cerana indica beehive in the Swiss Albino mice. J. Adv. Biotechnol. Exp. Ther. 2020, 3 , 128-134. [CrossRef]

41. Adnan, M.; Chy, M.N.U.; Rudra, S.; Tahamina, A.; Das, R.; Tanim, M.A.H.; Siddique, T.I.; Hoque, A.; Tasnim, S.M.; Paul, A.; et al. Evaluation of Bonamia semidigyna (Roxb.) for antioxidant, antibacterial, anthelmintic and cytotoxic properties with the involvement of polyphenols. Orient. Pharm. Exp. Med. 2019, 19, 187-199. [CrossRef]

42. Rahaman, M.M.; Rakib, A.; Mitra, S.; Tareq, A.T.; Emran, T.B.; Ud-Daula, S.A.F.M.; Amin, M.N.; Simal-Gandara, J. The Genus Curcuma and Inflammation: Overview of the Pharmacological Perspectives. Plants 2021, 10, 63.

43. Wilhelm, J.; Vytášek, R.; Uhlík, J.; Vajner, L. Oxidative stress in the developing rat brain due to production of reactive oxygen and nitrogen species. Oxidative Med. Cell. Longev. 2016, 2016, 1-12. [CrossRef]

44. Pechan, P.A.; Chowdhury, K.; Seifert, W. Free radicals induce gene expression of NGF and bFGF in rat astrocyte culture. Neuroreport 1992, 3, 469-472. [CrossRef]

45. 45. Jyoti, M.A.; Barua, N.; Hossain, M.S.; Hoque, M.; Bristy, T.A.; Mahmud, S.; Kamruzzaman; Adnan, M.; Chy, M.N.U.; Paul, A.; et al. Unravelling the biological activities of the Byttneria pilosa leaves using experimental and computational approaches. Molecules 2020, 25, 4737. [CrossRef]

46. Sinclair, A.; Barnett, A.; Lunec, J. Free radicals and antioxidant systems in health and disease. Br. J. Hosp. Med. 1990, $43,334$.

47. Rahman, J.; Tareq, A.M.; Hossain, M.M.; Sakib, S.A.; Islam, M.N.; Uddin, A.B.M.N.; Hoque, M.; Nasrin, M.S.; Ali, M.H.; Caiazzo, E.; et al. Biological evaluation, DFT calculations and molecular docking studies on the antidepressant and cytotoxicity activities of Cycas pectinata Buch.-Ham. Compounds. Pharmaceuticals 2020, 13, 232. [CrossRef] [PubMed]

48. Banu, N.; Alam, N.; Islam, M.N.; Islam, S.; Sakib, S.A.; Hanif, N.B.; Chowdhury, M.R.; Tareq, A.M.; Chowdhury, K.H.; Jahan, S.; et al. Insightful Valorization of the Biological Activities of Pani Heloch Leaves through Experimental and Computer-Aided Mechanisms. Molecules 2020, 25, 5153. [CrossRef] [PubMed]

49. Hajimehdipoor, H.; Shahrestani, R.; Shekarchi, M. Investigating the synergistic antioxidant effects of some flavonoid and phenolic compounds. Res. J. Pharmacogn. 2014, 1, 35-40.

50. Pietta, P.-G. Flavonoids as antioxidants. J. Nat. Prod. 2000, 63, 1035-1042. [CrossRef] [PubMed]

51. Uddin, M.Z.; Paul, A.; Rakib, A.; Sami, S.A.; Mahmud, S.; Rana, M.S.; Hossain, S.; Tareq, A.M.; Dutta, M.; Emran, T.B.; et al. Chemical Profiles and Pharmacological Properties with In Silico Studies on Elatostema papillosum Wedd. Molecules 2021, $26,809$. [CrossRef] [PubMed]

52. Krishnaraju, A.V.; Rao, T.V.; Sundararaju, D.; Vanisree, M.; Tsay, H.-S.; Subbaraju, G.V. Assessment of bioactivity of Indian medicinal plants using brine shrimp (Artemia salina) lethality assay. Int. J. Appl. Sci. Eng. 2005, 3, 125-134.

53. Pourfraidon, Z.; Sharma, C. Biological activity of prominent anti-cancer plants using Brine Shrimp Lethality Test. J. Microb. World 2009, 2, 201-204.

54. Guha, B.; Arman, M.; Islam, M.N.; Tareq, S.M.; Rahman, M.M.; Sakib, S.A.; Mutsuddy, R.; Tareq, A.M.; Emran, T.B.; Alqahtani, A.M. Unveiling pharmacological studies provide new insights on Mangifera longipes and Quercus gomeziana. Saudi J. Biol. Sci. 2021, 28, 183-190. [CrossRef]

55. Hasanat, A.; Kabir, M.S.H.; Ansari, M.A.; Chowdhury, T.A.; Hossain, M.M.; Islam, M.N.; Ahmed, S.; Chy, M.N.U.; Adnan, M.; Kamal, A.M. Ficus cunia Buch.-Ham. ex Roxb.(leaves): An experimental evaluation of the cytotoxicity, thrombolytic, analgesic and neuropharmacological activities of its methanol extract. J. Basic Clin. Physiol. Pharmacol. 2019, 30, 30. [CrossRef]

56. Syahmi, A.R.M.; Vijayarathna, S.; Sasidharan, S.; Latha, L.Y.; Kwan, Y.P.; Lau, Y.L.; Shin, L.N.; Chen, Y. Acute oral toxicity and brine shrimp lethality of Elaeis guineensis Jacq., (oil palm leaf) methanol extract. Molecules 2010, 15, 8111-8121. [CrossRef]

57. Bristy, T.A.; Barua, N.; Tareq, A.M.; Sakib, S.A.; Etu, S.T.; Chowdhury, K.H.; Jyoti, M.A.; Aziz, M.; Ibn, A.; Reza, A. Deciphering the pharmacological properties of methanol extract of Psychotria calocarpa leaves by in vivo, in vitro and in silico approaches. Pharmaceuticals 2020, 13, 183. [CrossRef] [PubMed]

58. Al Mahmud, Z.; Emran, T.B.; Qais, N.; Bachar, S.C.; Sarker, M.; Uddin, M.M.N. Evaluation of analgesic, anti-inflammatory, thrombolytic and hepatoprotective activities of roots of Premna esculenta (Roxb). J. Basic Clin. Physiol. Pharmacol. 2016, 27, 63-70. [CrossRef]

59. Akter, S.; Shah, M.; Tareq, A.M.; Nasrin, M.S.; Rahman, M.A.; Babar, Z.; Haque, M.A.; Royhan, M.J.; Mamun, M.N.; Reza, A.A. Pharmacological effect of methanolic and hydro-alcoholic extract of Coconut endocarp. J. Adv. Biotechnol. Exp. Ther. 2020, 3 , 171-181. [CrossRef] 
60. Rakib, A.; Ahmed, S.; Islam, M.A.; Haye, A.; Uddin, S.N.; Uddin, M.M.N.; Hossain, M.K.; Paul, A.; Emran, T.B. Antipyretic and hepatoprotective potential of Tinospora crispa and investigation of possible lead compounds through in silico approaches. Food Sci. Nutr. 2020, 8, 547-556. [CrossRef] [PubMed]

61. Hommel, M.; Cornu, C.; Boutitie, F.; Boissel, J.P.; Multicenter Acute Stroke Trial—Europe Study Group. Thrombolytic therapy with streptokinase in acute ischemic stroke. N. Engl. J. Med. 1996, 335, 145-150.

62. Di Cera, E.; Dang, Q.; Ayala, Y. Molecular mechanisms of thrombin function. Cell. Mol. Life Sci. CMLS 1997, 53, 701-730. [CrossRef]

63. Shifah, F.; Tareq, A.M.; Sayeed, M.A.; Islam, M.N.; Emran, T.B.; Ullah, M.A.; Mukit, M.A.; Ullah, M. Antidiarrheal, cytotoxic and thrombolytic activities of methanolic extract of Hedychium coccineum leaves. J. Adv. Biotechnol. Exp. Ther. 2020, 3, 77-83. [CrossRef]

64. Emran, T.B.; Rahman, M.A.; Uddin, M.M.N.; Rahman, M.M.; Uddin, M.Z.; Dash, R.; Layzu, C. Effects of organic extracts and their different fractions of five Bangladeshi plants on in vitro thrombolysis. BMC Complement. Altern. Med. 2015, 15, 128. [CrossRef] [PubMed]

65. Rakib, A.; Ahmed, S.; Islam, M.A.; Uddin, M.M.N.; Paul, A.; Chy, M.N.U.; Emran, T.B.; Seidel, V. Pharmacological studies on the antinociceptive, anxiolytic and antidepressant activity of Tinospora crispa. Phytother. Res. 2020, 34, 2978-2984. [CrossRef]

66. Adnan, M.; Chy, M.; Uddin, N.; Kama, A.; Azad, M.; Kalam, O.; Chowdhury, K.A.A.; Kabir, M.S.H.; Gupta, S.D.; Chowdhury, M. Comparative Study of Piper sylvaticum Roxb. Leaves and Stems for Anxiolytic and Antioxidant Properties Through in vivo, in vitro, and in silico Approaches. Biomedicines 2020, 8, 68. [CrossRef]

67. Dutta, T.; Paul, A.; Majumder, M.; Sultan, R.A.; Emran, T.B. Pharmacological evidence for the use of Cissus assamica as a medicinal plant in the management of pain and pyrexia. Biochem. Biophys. Rep. 2020, 21, 100715. [CrossRef] [PubMed]

68. Tayab, M.A.; Chowdhury, K.A.A.; Jabed, M.; Mohammed Tareq, S.; Kamal, A.T.M.M.; Islam, M.N.; Uddin, A.M.K.; Hossain, M.A.; Emran, T.B.; Simal-Gandara, J. Antioxidant-Rich Woodfordia fruticosa Leaf Extract Alleviates Depressive-Like Behaviors and Impede Hyperglycemia. Plants 2021, 10, 287. [CrossRef] [PubMed]

69. Adnan, M.; Chy, M.; Uddin, N.; Kamal, A.; Chowdhury, K.A.A.; Rahman, M.; Reza, A.; Moniruzzaman, M.; Rony, S.R.; Nasrin, M. Intervention in Neuropsychiatric Disorders by Suppressing Inflammatory and Oxidative Stress Signal and Exploration of In Silico Studies for Potential Lead Compounds from Holigarna caustica (Dennst.) Oken leaves. Biomolecules 2020, $10,561$. [CrossRef] [PubMed]

70. Yesmin, S.; Paul, A.; Naz, T.; Rahman, A.B.M.A.; Akhter, S.F.; Wahed, M.I.I.; Emran, T.B.; Siddiqui, S.A. Membrane stabilization as a mechanism of the anti-inflammatory activity of ethanolic root extract of Choi (Piper chaba). Clin. Phytosci. 2020, 6, 59. [CrossRef]

71. Black, C.N.; Bot, M.; Scheffer, P.G.; Cuijpers, P.; Penninx, B.W. Is depression associated with increased oxidative stress? A systematic review and meta-analysis. Psychoneuroendocrinology 2015, 51, 164-175. [CrossRef] [PubMed]

72. Ahmed, S.; Rakib, A.; Islam, M.A.; Khanam, B.H.; Faiz, F.B.; Paul, A.; Chy, M.N.U.; Bhuiya, N.M.A.; Uddin, M.M.N.; Ullah, S.A. In vivo and in vitro pharmacological activities of Tacca integrifolia rhizome and investigation of possible lead compounds against breast cancer through in silico approaches. Clin. Phytosci. 2019, 5, 36. [CrossRef] 